\title{
Engineering
}

\section{Plasticity in Chevron-notch fracture toughness testing}

\author{
T.J. Grant ${ }^{a}$, L. Weber ${ }^{b, *}$, A. Mortensen ${ }^{b, 1}$ \\ ${ }^{a}$ Warburg Dillon Read, London, UK \\ ${ }^{\mathrm{b}}$ Laboratory of Mechanical Metallurgy, Department of Materials, Swiss Federal Institute of Technology in Lausanne (EPFL), MX-D \\ Ecublens, CH-1015 Lausanne, Switzerland
}

Received 4 November 1999; received in revised form 18 May 2000; accepted 26 June 2000

\begin{abstract}
The behavior of Chevron-notched fracture specimens during unload/reload cycles conducted near peak load is analyzed for an elastic/perfectly plastic material using Irwin's simplified analysis of crack tip plasticity. A linear relationship is found to link the plasticity parameter $p$ with the ratio of minimum allowable specimen thickness $B_{\mathrm{c}}$ (both as defined in ASTM Standard E1304) to the actual specimen thickness $B$. This relationship agrees with data measured in this work, and with data from the literature (with the exception of one study), although the analysis underestimates the coefficient of proportionality. The average value of $p$ at the minimum required specimen thickness (i.e., at $B_{\mathrm{c}} / B=1$ ) is found to be significantly higher than is allowed by the standard. This suggests that the two requirements defined in the standard to ascertain small scale yielding conditions should be harmonized for consistency with one another. () 2000 Elsevier Science Ltd. All rights reserved.
\end{abstract}

Keywords: Metal-matrix composites; Aluminum alloys; Chevron-notched specimen configuration; Toughness testing; Plasticity

\section{Introduction}

Plane-strain fracture toughness testing using Chevron-notched short rod or short bar specimens according to ASTM Standard E1304 features several advantages and drawbacks compared with the more conventional fracture toughness test conducted on CT specimens according to ASTM Standard E399. Among its advantages, two are most frequently cited: (i) the minimum specimen geometry in ASTM E1304 is smaller than that prescribed by ASTM E399 and (ii) there is no need for pre-cracking the specimen in fatigue [1]. For these reasons, Chevron-notched samples have been used in attempts to measure the fracture toughness of a variety of materials, ranging from brittle ceramics to more ductile metals, and also including polymers and metal/ceramic composites. Agreement between the two toughness measurement methods for metallic materials has been verified by several authors [2-8], to show that, for most materials exhibiting a

\footnotetext{
${ }^{*}$ Corresponding author. Tel.: +41-21-693-2934; fax: +41-21-693-4664.

E-mail address: ludger.weber@epfl.ch (L. Weber).

${ }^{1}$ Also corresponding author.
} 


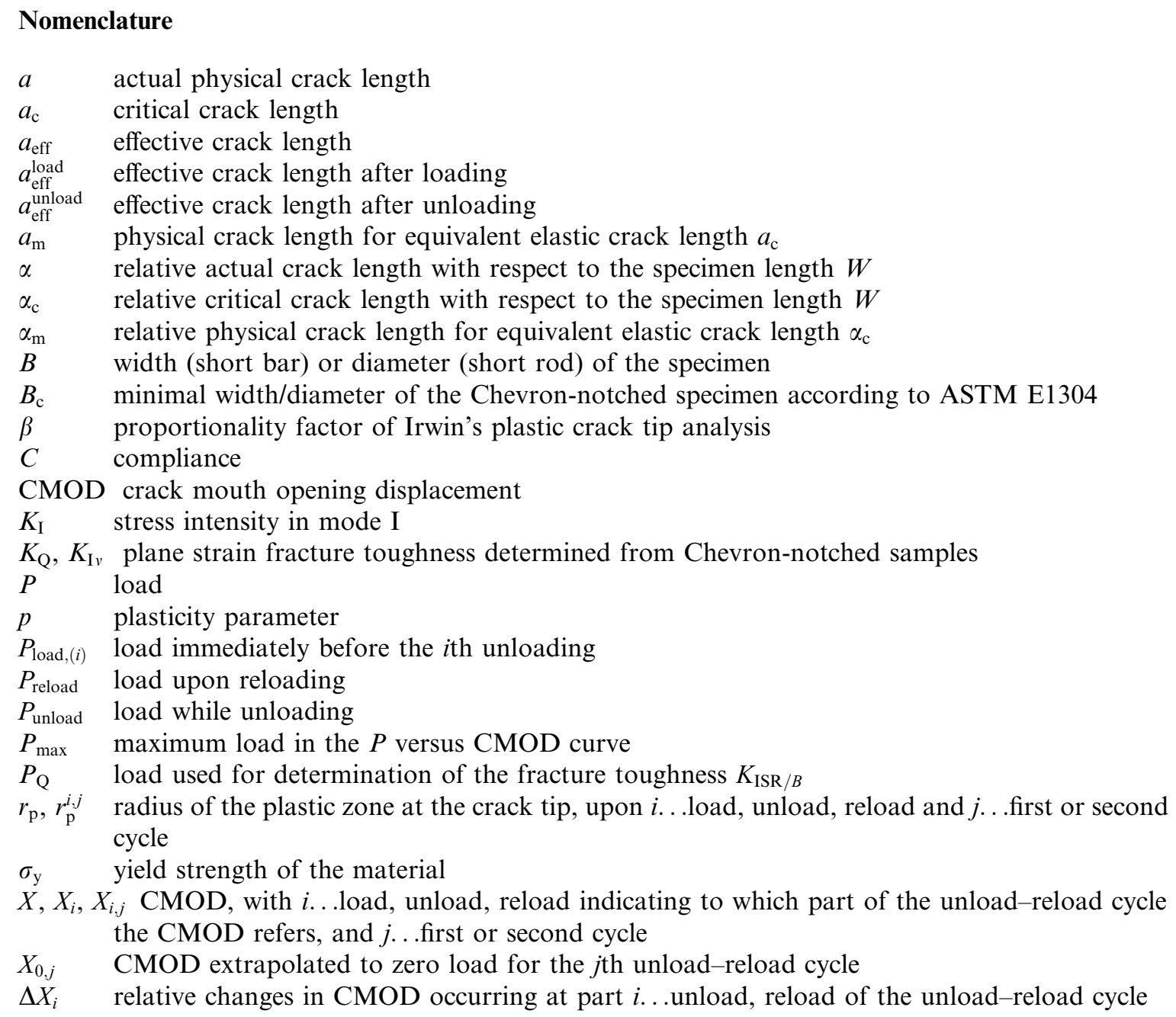

flat $R$-curve, $K_{\text {Ic }}$ (the plane strain fracture toughness according to ASTM Standard E399) and $K_{\text {Iv }}$ (the plane strain fracture toughness determined with a short rod/bar specimen according to ASTM Standard E1304) are in good agreement below 20-30 $\mathrm{MPa} \mathrm{m}^{1 / 2}$.

Both of these standardized testing procedures are based on linear elastic fracture mechanics. When used for testing of materials that are not strictly elastic, therefore, their applicability falls subject to the condition that non-linear deformation be limited to a volume of material surrounding the crack tip that is sufficiently small compared to the specimen size. For ductile metals, this condition, coupled with the requirement that the majority of the crack front be in plane strain, translates in ASTM E399 into the need for specimen dimensions to satisfy the following criteria:

$$
\text { (i) } a \text { and } B \geqslant 2.5\left(\frac{K_{\mathrm{Ic}}}{\sigma_{\mathrm{y}}}\right)^{2} \text {, }
$$


(ii) $W \geqslant 5\left(\frac{K_{\mathrm{Ic}}}{\sigma_{\mathrm{y}}}\right)^{2}$,

where $a, B$ and $W$ are the crack length, specimen diameter or thickness, and specimen width along the crack plane, respectively; $\sigma_{\mathrm{y}}$ is the $0.2 \%$ offset yield strength of the material and $K_{\mathrm{Ic}}$ its plane-strain fracture toughness.

Comparatively, the minimum sample size that is explicitly required in ASTM E1304 is far less stringent. Indeed, the explicit dimensional requirement set by the standard is

$$
B \geqslant 1.25\left(\frac{K_{\mathrm{I} v}}{\sigma_{\mathrm{y}}}\right)^{2} \equiv B_{\mathrm{c}},
$$

where $K_{\mathrm{I} v}$ is the plane strain toughness measured according to ASTM E1304, and $B_{\mathrm{c}}$ is the required minimum specimen dimension. Satisfaction of this criterion ensures fulfillment of similar criteria for all other relevant dimensions, since the sample geometry and critical crack position for the measurement are specified explicitly or implicitly by the test standard. This less stringent explicit size requirement in ASTM E1304 compared with ASTM E399 is justified by the presence of side grooves along crack edges, which promote plane-strain conditions at the crack tip; it is also supported by experiment $[2,9]$.

There is, however, a second limitation placed on the extent of crack-tip plasticity in the testing of Chevron-notched bars according to ASTM E1304, defined using a plasticity parameter $p$, which is measured by conducting two loading/unloading cycles during the test, and computed using the resulting plot of applied load $P$ versus crack mouth opening displacement (CMOD), $X$. More specifically, parameter $p$ is defined as follows.

Consider the load $P$ versus CMOD curve traced during testing of a Chevron-notched fracture specimen, Fig. 1. As the specimen crack mouth is pried open, the crack extends gradually and in stable fashion (we exclude for simplicity crack jump behavior in what follows). At least two unload/reload cycles are conducted during the test sufficiently near the critical crack length $a_{\mathrm{c}}$, which corresponds to the minimum value

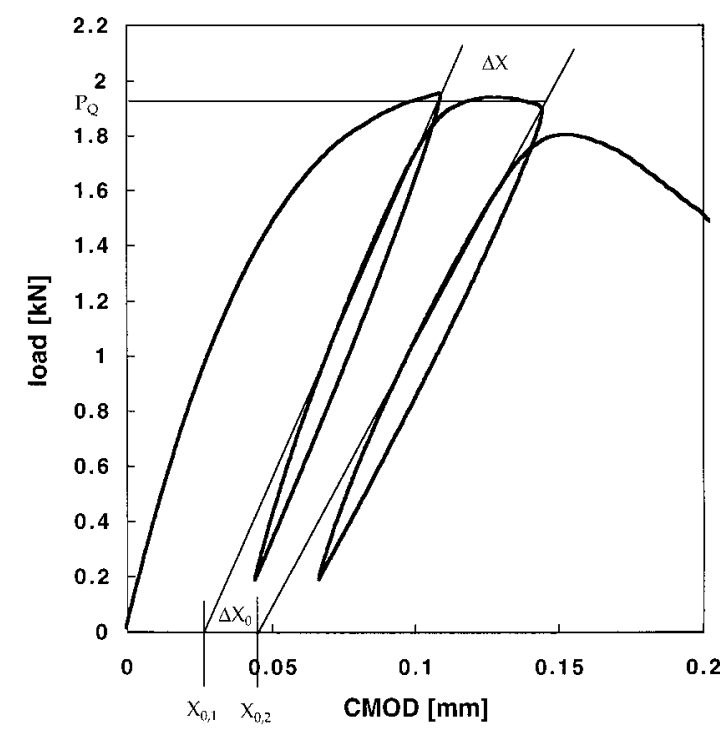

Fig. 1. Typical load versus CMOD curve for a Chevron-notch fracture toughness test with repeated unloading and reloading. The load $P_{\mathrm{Q}}$ is determined by a horizontal line which produces equal shaded areas above and below the line. The values of $\Delta X$ and $\Delta X_{0}$ are found by measuring the intercept between the two unloading lines both at $P=P_{\mathrm{Q}}$ and $P=0$. 
of the geometry-dependent portion of the elastic stress intensity factor for the given Chevron-notched fracture specimen geometry. Because the crack length is near $a_{\mathrm{c}}$, the maximum load $P$ for both unload/ reload cycles is - for a material exhibiting a flat $R$-curve - at roughly the same value $P_{\mathrm{Q}}$. Defining $\Delta X$ as the difference in CMOD for these two unload/reload cycles at load $P_{\mathrm{Q}}$, and $\Delta X_{0}$ as the difference in CMOD at zero load extrapolated using the point prior to unloading and the point in the reloading curve at half the initial load of each cycle, the plasticity parameter $p$ is defined as

$$
p=\frac{\Delta X_{0}}{\Delta X}
$$

According to the standard, the load $P_{\mathrm{Q}}$ is in fact chosen such that the area between a horizontal line at load $P_{\mathrm{Q}}$ and the actual load versus CMOD curve be equal above and below the horizontal line, as depicted in Fig. 1.

With a purely elastic material, unloading at any stage of the test results in $P$ versus CMOD lines that all go through the origin; hence, $p$ will be zero. At the other extreme, if the limit load of the elastic-plastic material is exceeded and general yielding has occurred along the remaining uncracked ligament or within the two bent cantilevers on either side of the crack, the specimen reduces to a plastic hinge, the CMOD increases without crack extension, and the slopes at unloading become parallel; $p$ is then equal to one. In a typical elastic-plastic test, the behavior is intermediate between these two extremes, and finite values of $p$ less than one are expected.

Parameter $p$ thus defined by the standard is also affected by the presence of macroscopic residual stresses (e.g. in sheet metal): tensile residual stresses near the specimen surface tend to increase $p$, while compressive peripheral residual stresses tend to decrease $p$, potentially causing the observation of negative values for this parameter.

ASTM E1304 places an allowable range of $-0.05 \leqslant p \leqslant 0.1$ for validity of the measured value of $K_{\mathrm{I} v}$. This condition has the particular advantage of detecting and limiting the influence of residual stresses in the material on the measured toughness value; however, because for a given specimen size greater crack tip plasticity always increases $p$, this requirement also places a second, indirect and implicit but nonetheless tangible, lower limit on allowable specimen dimensions.

We examine in what follows the link that exists between these two limits placed on the extent of crack tip plasticity and, hence, on sample dimensions. To this end, we use the elastic/perfectly plastic analysis of crack tip plasticity proposed by Rice for fatigue cracks under small scale yielding conditions [10] to establish a relatively simple and explicit relation linking $p$, in the absence of residual stress effects, with specimen size, which depends only on the two parameters $\sigma_{\mathrm{y}}$ and $K_{\mathrm{I} v}$. We then confront this relation with experimental data, and re-examine size requirements in toughness testing of elasto-plastic materials using Chevron-notched specimens.

\section{Relating parameter $p$ to the plastic zone size}

Irwin's simplified analysis [11] of the plastic zone surrounding a Mode I plane-strain crack tip in an elastic/perfectly plastic material yields a plastic zone radius $r_{\mathrm{p}}$ equal to

$$
r_{\mathrm{p}}=\frac{1}{\beta \pi}\left(\frac{K_{\mathrm{I}}}{\sigma_{\mathrm{y}}}\right)^{2},
$$

where $\sigma_{\mathrm{y}}$ is the yield stress of the material and $K_{\mathrm{I}}$ is the stress intensity factor characterizing the stress field in the elastic material surrounding the crack tip plastic zone. Term $\beta$ is a constant, the value of which was proposed by Irwin to be near six; however, this constant varies somewhat depending on the degree of triaxiality that is assumed to prevail near the yield locus in the material surrounding the plane strain crack 
tip under consideration [11]. In plane stress, $\beta$ equals two. By comparing Eq. (5) with Eqs. (1) to (3), it is immediately evident that sample critical dimensions, including $B_{\mathrm{c}}$ in the short bar specimen, are multiples of the crack tip plastic zone size.

In the absence of residual stresses, parameter $p$ as defined in Eq. (4) is potentially influenced by three plasticity effects: (i) local plasticity in the vicinity of the crack tip, (ii) plastic deformation in the arms of the Chevron-notched specimen and (iii) general yielding of the ligament joining the crack tip with the sample surfaces. As the Chevron-notch standard is valid for small scale yielding (SSY) conditions only, the last two factors are excluded from consideration; we therefore restrict attention in what follows to factor (i). In order to justify that restriction, an estimate of onset of large-scale yielding by a limit-load calculation is given in the appendix.

It is well known that, under small scale yielding conditions, the actual crack length, $a$, is less than that of the crack to which the surrounding elastic $K$-dominated stress field would correspond in a fully elastic material under applied load $P$. This latter crack length is defined as the effective crack length, $a_{\mathrm{eff}}$. Irwin's analysis leading to Eq. (5) yields the result:

$$
a_{\mathrm{eff}}=a+r_{\mathrm{p}}
$$

The stress intensity factor in Eq. (5) corresponds rightly to a purely elastic sample of the geometry and size under consideration, containing a crack of length $a_{\mathrm{eff}}$, under load $P$.

The CMOD $X_{\text {load }}$ measured while loading the sample under load $P_{\text {load }}$ at physical crack length $a$ is thus given by

$$
X_{\text {load }}=P_{\text {load }} C\left(a_{\text {eff }}^{\text {load }}\right),
$$

where $C\left(a_{\mathrm{eff}}^{\mathrm{load}}\right)$ is the compliance of a purely elastic specimen of identical geometry as that of the specimen containing a crack of length $a_{\mathrm{eff}}^{\text {load }}$, with $a_{\mathrm{eff}}^{\text {load }}$ given by Eq. (6) with $P=P_{\text {load }}$, and $r_{\mathrm{p}}$ equal to

$$
r_{p}^{\text {load }}=\frac{1}{\beta \pi}\left(\frac{K_{\mathrm{I}}\left(a_{\mathrm{eff}}^{\text {load }}, P_{\text {load }}\right)}{\sigma_{\mathrm{y}}}\right)^{2} .
$$

Following Rice's analysis of the behavior of the crack tip plastic zone during unloading and reloading [10], the evolution of the CMOD during an unloading-reloading cycle as required by Standard E1304 can then be derived with relative simplicity as follows.

When the load is decreased after reaching a value $P_{\text {load }}$, reversed (compressive) plastic yielding reduces the size of the crack tip plastic zone formed on loading to $P_{\text {load }}$ and the material surrounding this region of reverse plasticity unloads elastically. The resulting stress field in the elastic region surrounding the diminished plastic zone formed upon unloading to $P_{\text {unload }}$ is the superposition of (i) the elastic-plastic field present when the load reached $P_{\text {load }}$, and (ii) the negative of the elastic field surrounding a crack of length, $a$, in an elastic-plastic material of yield strength $2 \sigma_{\mathrm{y}}$ under load $\left(P_{\text {load }}-P_{\text {unload }}\right)$. The effective crack length corresponding to this resulting stress field is given by

$$
a_{\mathrm{eff}}^{\mathrm{unload}}=a+r_{\mathrm{p}}^{\mathrm{unload}}
$$

where

$$
r_{\mathrm{p}}^{\text {unload }}=\frac{1}{\beta \pi}\left(\frac{K_{\mathrm{I}}\left(a_{\mathrm{eff}}^{\text {unload }}, P_{\text {load }}-P_{\text {unload }}\right)}{2 \sigma_{\mathrm{y}}}\right)^{2} .
$$

The reduction in CMOD, $\overline{\Delta X}_{\text {unload }}$, after unloading to load $P_{\text {unload }}$ from load $P_{\text {load }}$ is hence given by

$$
\overline{\Delta X}_{\text {unload }}=\left(P_{\text {load }}-P_{\text {unload }}\right) C\left(a_{\text {eff }}^{\text {unload }}\right),
$$


where $C\left(a_{\mathrm{eff}}^{\text {unload }}\right)$ stands for the compliance of a purely elastic specimen containing a crack of length $a_{\mathrm{eff}}^{\text {unload }}$. The CMOD itself, $X_{\text {unload }}$, reached after unloading to load $P_{\text {unload }}$ from initial load $P_{\text {load }}$ is given by

$$
X_{\text {unload }}=X_{\text {load }}-\overline{\Delta X}_{\text {unload }} \text {. }
$$

Since the zone of crack tip plasticity after full unloading is one-fourth the plastic zone created on loading, $a_{\mathrm{eff}}^{\text {load }}$ exceeds $a_{\mathrm{eff}}^{\text {unload }}$ by three quarters of the advancing crack tip plastic zone radius, $r_{\mathrm{p}}^{\text {load }}$. As a consequence, $C\left(a_{\mathrm{eff}}^{\text {load }}\right)$ is smaller than $C\left(a_{\mathrm{eff}}^{\text {load }}\right)$, and the crack mouth remains slightly open. Since $C\left(a_{\mathrm{eff}}^{\text {unload }}\right)$ gradually increases as unloading progresses, this simple analysis also predicts that the plot of $P$ versus $X$ during unloading is not linear. Instead, it traces a curve that is concave upwards; this is observed in experiments, cf. Fig. 1. We also note that if the true crack position is to be detected, the best procedure would be to measure the slope of this unloading curve immediately upon unloading, when $r_{\mathrm{p}}^{\text {unload }}$ is very small and $a_{\mathrm{eff}}^{\text {unload }} \approx a\left(\right.$ Eq. (9)), as is practiced in $J_{\text {Ic }}$ testing according to Standard ASTM E1737 by limiting the maximum unload/reload range.

Upon reloading after reaching a lower load $P_{\text {unload, }}$, a similar argument holds for the changes in CMOD upon reloading to load $P_{\text {reload }}$ :

$$
\overline{\Delta X}_{\text {reload }}=\left(P_{\text {reload }}-P_{\text {unload }}\right) C\left(a_{\text {eff }}^{\text {reload }}\right)
$$

with, again,

$$
\begin{aligned}
& a_{\text {eff }}^{\text {reload }}=a+r_{\mathrm{p}}^{\text {reload }}, \\
& r_{\mathrm{p}}=\frac{1}{\beta \pi}\left(\frac{K_{\mathrm{I}}\left(a_{\mathrm{eff}}^{\text {reload }}, P_{\text {reload }}-P_{\text {unload }}\right.}{2 \sigma_{\mathrm{y}}}\right)^{2} .
\end{aligned}
$$

The CMOD after reloading, $X_{\text {reload }}$, is thus

$$
X_{\text {reload }}=X_{\text {load }}-\overline{\Delta X}_{\text {unload }}+\overline{\Delta X}_{\text {reload }} \text {. }
$$

This curve is now concave downwards, since $a_{\text {eff }}^{\text {reload }}$ increases as $P_{\text {reload }}$ increases. Hence, the hysteretic shape of unload/reload $P$ versus $X$ curves is accounted for.

For the determination of the $p$ value according to ASTM E1304, the residual CMOD $X_{0,1}$ at zero extrapolated load of the first unloading-reloading cycle is determined by drawing a line through the point immediately before unloading from load $P$ and the point which corresponds to $0.5 P$ along the curve traced by the plot of $P$ versus $X$ upon reloading, as was suggested by Barker [12]. This residual CMOD is thus given by

$$
X_{0,1}=2 X_{\text {reload }, 1}-X_{\text {load }, 1} \text {. }
$$

Similarly, for a second unloading-reloading cycle

$$
X_{0,2}=2 X_{\text {reload }, 2}-X_{\text {load }, 2} \text {. }
$$

On unloading according to the standard, the load is lowered to between $3 \%$ and $10 \%$ of the load reached immediately before unloading. Fixing this value at $10 \%$ and combining Eqs. (16) and (17) with Eqs. (7), (10)-(12) and (15) yields for the extrapolated residual CMOD values, $X_{0,1}, X_{0,2}$ :

$$
X_{0, i}=X_{\text {load }, i}-1.8 P_{\text {load }, i} C\left(a_{\mathrm{eff}}^{\text {unload }, i}\right)+0.8 P_{\text {load }, i} C\left(a_{\mathrm{eff}}^{\text {reload }, i}\right),
$$

where $i=1$ or 2 denotes the unloading-reloading cycle.

We assume that the two unloading cycles are performed in a narrow range about the peak $P_{\max }$ of the load versus CMOD curve, where $\mathrm{d} P / \mathrm{d} X$ is near zero; this is justified by the fact that the standard requires that the load near the point of measurement, $P_{\mathrm{Q}}$, be within $10 \%$ of the peak load. With this assumption, two simplifications can be made 
(i) $P_{\text {load }, 1}=P_{\text {load }, 2}=P_{\max }$,

(ii) the function of the effective crack length $f\left(a_{\mathrm{eff}}\right)$ defined by the relationship:

$$
K_{\mathrm{I}}(a, P)=f(a) P
$$

for a fully elastic specimen is near its minimum. Hence, $a_{\mathrm{eff}}^{\text {load }}$ is near $a_{\mathrm{c}}$, the critical crack length for which $P$ reaches a maximum for the specimen geometry considered with purely elastic material.

Since the crack advances when the stress intensity factor surrounding its tip equals the toughness of the material $K_{\mathrm{I} v}$, we also know that

$$
r_{\mathrm{p}}^{\text {load }, i}=\frac{1}{\beta \pi}\left(\frac{K_{\mathrm{I} v}}{\sigma_{\mathrm{y}}}\right)^{2} .
$$

Hence, in the vicinity of the maximum of the $P$ versus $X$ curve, the physical crack length, $a$, is near a value $a_{\mathrm{m}}$ given by

$$
a_{\mathrm{m}}=a_{\mathrm{c}}-\frac{1}{\beta \pi}\left(\frac{K_{\mathrm{Iv}}}{\sigma_{\mathrm{y}}}\right)^{2} .
$$

By definition (Eq. (4)), the plasticity parameter $p$ equals

$$
p=\frac{X_{0,2}-X_{0,1}}{X_{\text {load }, 2}-X_{\text {load }, 1}} .
$$

If the crack has advanced by $\Delta a$ between the two cycles, since $\Delta a=\Delta a_{\mathrm{eff}}$ at constant $r_{\mathrm{p}}$, we can write

$$
X_{\mathrm{load}, 2}-X_{\mathrm{load}, 1} \approx P_{\max }\left(\frac{\mathrm{d} C}{\mathrm{~d} a}\right)_{a=a_{\mathrm{c}}} \Delta a .
$$

To determine $X_{0,2}-X_{0,1}$, we assume that the minimum of $f(a)$ near $a=a_{\mathrm{c}}$ is sufficiently broad for $f(a)$ to remain roughly constant between $a=a_{\mathrm{m}}$ and $a=a_{\mathrm{c}}$ (this minimum is, indeed, relatively broad for usual Chevron-notched sample geometries [13-16]). Stress intensities then remain roughly proportional to the applied load $P$ during the unload/reload cycles. The sizes of zones of reversed plasticity are then, roughly $\left(\left(P_{\text {load }}-P_{\text {unload }}\right) / P_{\text {load }}\right)^{2}$ and $\left(\left(P_{\text {reload }}-P_{\text {unload }}\right) / P_{\text {load }}\right)^{2}$ (with present values for $P_{\text {reload }}$ and $P_{\text {unload }}$, respectively 0.2 and 0.06$)$ times $r_{\mathrm{p}}$. As a consequence, Eq. (18) yields

$$
X_{0,2}-X_{0,1} \approx X_{\mathrm{load}, 2}-X_{\text {load }, 1}-1.8 P_{\max }\left(\frac{\mathrm{d} C}{\mathrm{~d} a}\right)_{a=a_{\mathrm{m}}+0.2 r_{\mathrm{p}}} \Delta a+0.8 P_{\max }\left(\frac{\mathrm{d} C}{\mathrm{~d} a}\right)_{a=a_{\mathrm{m}}+0.06 r_{\mathrm{p}}} \Delta a .
$$

The plasticity parameter $p$ is thus given as

$$
p=1-1.8 \frac{(\mathrm{d} C / \mathrm{d} a)_{a=a_{\mathrm{m}}+0.2 r_{\mathrm{p}}}}{(\mathrm{d} C / \mathrm{d} a)_{a=a_{\mathrm{c}}}}+0.8 \frac{(\mathrm{d} C / \mathrm{d} a)_{a=a_{\mathrm{m}}+0.06 r_{\mathrm{p}}}}{(\mathrm{d} C / \mathrm{d} a)_{a=a_{\mathrm{c}}}} .
$$

The denominator of this expression is a function only of specimen geometry. The numerator, on the other hand, depends, for a given specimen geometry, also on the plastic zone size $r_{\mathrm{p}}$ surrounding the advancing crack near the maximum of the load versus CMOD curve. For a given specimen geometry, hence, $B_{\mathrm{c}}$ and $p$ are strictly interdependent (within assumptions of the present derivation, of course). Both quantities are prescribed or predicted to vary solely as a function of the ratio of fracture toughness to yield strength of the material. Furthermore, this relationship will remain valid regardless of the precise definition of parameter $p$.

Recasting Eq. (26) in terms of the normalized compliance $C^{*}$ (using the terminology of Ref. [6] and crack-length versus compliance data from Ref. [17]): 


$$
C^{*}=C \frac{E B}{2},
$$

where $B$ is the specimen thickness or diameter, and the dimensionless crack length $\alpha$ is given by

$$
\alpha=\frac{a}{W},
$$

where $W$ is the specimen width (i.e. length), $p$ becomes

$$
p=1-1.8 \frac{\left(\mathrm{d} C^{*} / \mathrm{d} \alpha\right)_{\alpha=\alpha_{\mathrm{m}, 0.2}}}{\left(\mathrm{~d} C^{*} / \mathrm{d} \alpha\right)_{\alpha=\alpha_{\mathrm{c}}}}+0.8 \frac{\left(\mathrm{d} C^{*} / \mathrm{d} \alpha\right)_{\alpha=\alpha_{\mathrm{m}, 0.06}}}{\left(\mathrm{~d} C^{*} / \mathrm{d} \alpha\right)_{\alpha=\alpha_{\mathrm{c}}}},
$$

with

$$
\begin{aligned}
\alpha_{\mathrm{m}, 0.2} & =\alpha_{\mathrm{c}}-\frac{0.8}{\beta \pi W}\left(\frac{K_{\mathrm{I} v}}{\sigma_{\mathrm{y}}}\right)^{2}=\alpha_{\mathrm{c}}-\frac{B_{\mathrm{c}}}{1.56 \beta \pi W} \\
\alpha_{\mathrm{m}, 0.06} & =\alpha_{\mathrm{c}}-\frac{0.94}{\beta \pi W}\left(\frac{K_{\mathrm{Iv}}}{\sigma_{\mathrm{y}}}\right)^{2}=\alpha_{\mathrm{c}}-\frac{B_{\mathrm{c}}}{1.33 \beta \pi W}
\end{aligned}
$$

where $B_{\mathrm{c}}$ is the critical specimen thickness specified by ASTM E1304, Eq. (3) [13]. The interdependence between the two criteria is thus made explicit. Furthermore, it is seen that, since $W$ and $B$ are in fixed proportions for a given sample geometry (including fixed $a_{0} / W$ ), the plasticity parameter is predicted to be a direct function of the ratio $B_{\mathrm{c}} / B$.

Resulting plots of $p$ versus $B_{\mathrm{c}} / B$ on a logarithmic scale are given in Fig. 2 for the short rod and short bar specimen geometries specified by ASTM, taking $\beta=6$ and 2 (which correspond, as mentioned, respectively, to Irwin's plane strain and plane stress expressions). It is seen that Eq. (29) defines an essentially linear relationship between $p$ and $B / B_{\mathrm{c}}$, which shifts by a constant as the value of $\beta$ changes and translates into a

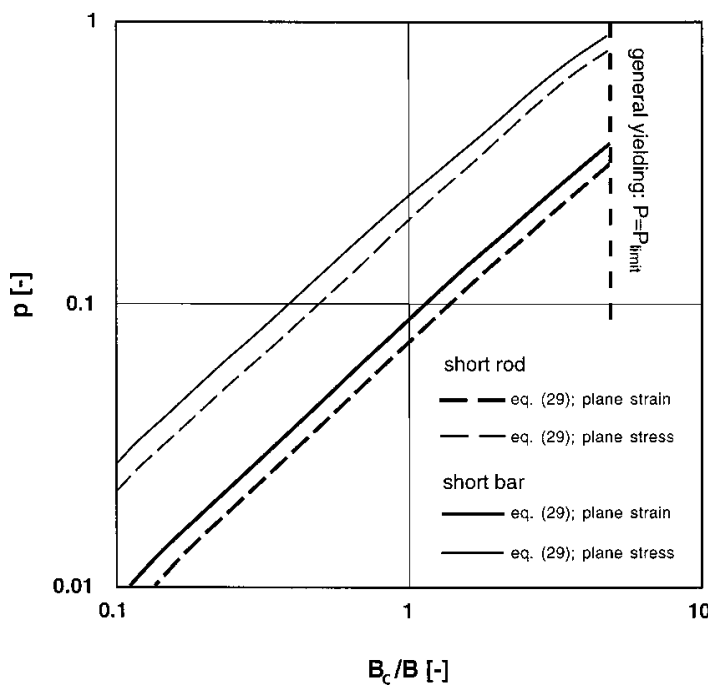

Fig. 2. Calculated data-pairs of $p$ versus $B_{\mathrm{c}} / B$ for the short rod and the short (square) bar specimen configuration in both plane-strain and plane-stress modes according to Eq. (29) up to the onset of large-scale yielding as estimated in the appendix. The results for the short rod and the short bar configurations are close to one another. 
variation of the constant of proportionality between $B / B_{\mathrm{c}}$ and $p$. The relationship is drawn up to the onset of large-scale yielding as estimated in the appendix.

We further note that a similar analysis for the short rod geometry yields predictions close to those for the short bar, Fig. 2, but are in general somewhat lower. Hence, both experimental results from short rod and short bar specimen are compared to the analysis.

\section{Experiments}

Fracture toughness measurements were conducted using Chevron-notch short bar specimens having standard dimensions of $20 \times 20 \times 31 \mathrm{~mm}^{3}(B \times 2 H \times W$ in the terminology of ASTM E1304 [13]). The notch was cut with an electron-discharge cutting device so that it was sharp and its flanks were straight.

Tests were conducted using a screw-driven general-purpose mechanical testing machine. The tests were run in crosshead speed control at a velocity of $0.5 \mathrm{~mm} \mathrm{~min}^{-1}$. The CMOD was measured using an extensometer of the type indicated in ASTM E1304-89 [13]. Materials that were tested included (i) a high-toughness spray-compacted AlCuMgAg alloy as described in Ref. [18], (ii) a high-strength spraycompacted $\mathrm{AlZnMg}(\mathrm{Cu})$ alloy as described in Ref. [19] and (iii) composites of $99.99 \%$ pure aluminum and Al-4.5\% $\mathrm{Cu}$ reinforced with $50 \mathrm{vol} . \%$ alumina or boron carbide particles of average diameter about 35,12 , and $5 \mu \mathrm{m}(320,600,1000$ grid particles, respectively). The composites were produced by gas-driven pressure infiltration; details concerning the processing, microstructures, and general properties of these composites can be found in Ref. [20].

Post-mortem investigation of the specimens showed that the crack path remained in-plane for all tests. The load at the critical crack length according to the standard, $P_{\mathrm{Q}}$, also fulfilled the requirement that it be no smaller than $90 \%$ of the peak load, $P_{\max }$.

Evaluation of the test procedure was done by comparing measured fracture toughness values for the $\mathrm{AlZnMg}(\mathrm{Cu})$ alloy, as well as for an $\mathrm{Al}-4.5 \mathrm{Cu}$ matrix composite reinforced with $35 \mu \mathrm{m}$ average diameter alumina particles, with values determined for the same materials and the same crack orientations using the compact tension specimen according to ASTM Standard E399. The Chevron-notched and compact tension specimens yielded values within 3\% of one another for the measured fracture toughness of these materials; in both tests, conditions set by the standards were obeyed. Hence, the testing procedure as implemented is considered to be reliable.

\section{Results and discussion}

An overview of $p$ and $B_{\mathrm{c}} / B$ data pairs from this investigation and from several sources in the literature $[2,9,21,22]$, gathered from relatively large variety of materials, is given in Fig. 3 . The emerging picture is that there is, indeed, a general trend towards larger $p$ values as the critical size to actual size ratio $B_{\mathrm{c}} / B$ increases. Scatter in the data as a whole is significant, but it is noteworthy that if one excludes data points given by Barker in Ref. [9], remaining data points, including values from an earlier publication by Barker [2], all fall far closer to one another and roughly delineate a band with a slope of 1 , as predicted by the analysis. Specimens increasingly falling short of the size requirement $\left(B_{\mathrm{c}} / B>1\right)$ approach a $p$ value of 1 , which corresponds to general yielding; the $B_{\mathrm{c}} / B$ ratio at which $p=1$ is reached is in good agreement with the prediction from the analysis given in the appendix and indicated in Fig. 3 by the vertical dashed line. Why the data of Ref. [9], which have been used by Barker to formulate another - purely heuristic - relationship between $p$ and $B_{\mathrm{c}} / B$, deviate from all other data is not clear to us. The data in Fig. 3 strongly suggest, however, that the curve that is drawn through the remaining data provides a correlation that can be used with greater confidence than the earlier power-law relation proposed by Barker in 1984 (Eq. (3) of Ref. [9]). 


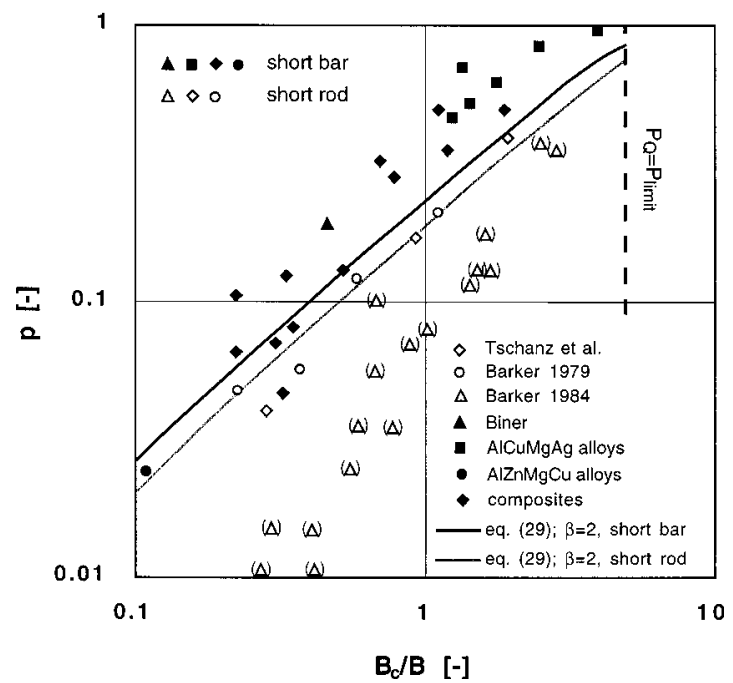

Fig. 3. Experimetal values of $p$ versus $B_{\mathrm{c}} / B$ for various materials. For comparison, the results from the analysis using a value of 2 for $\beta$ are included. The onset of large-scale yielding $\left(P_{\mathrm{Q}}=P_{\text {limit }}\right)$ as calculated in the appendix is indicated by the vertical dashed line.

Overall, it is seen that agreement of the data with Eq. (29) of the present analysis is quite satisfactory, as shown by the two continuous lines in Fig. 3. The black and grey line give the prediction for the short bar and short-rod configuration, respectively: the separation between these two curves is also roughly found experimentally between short-rod and short bar specimens. The value of parameter $\beta$ of 2 , which corresponds to these lines is, however, somewhat low compared to a value near 6 as would be expected for planestrain according to Irwin. We attribute this discrepancy to the many assumptions made in the analysis, which include in particular all simplifications inherent in the Irwin derivation yielding Eqs. (5) and (6), which were used as a starting point in the present derivation.

Apart from the somewhat low value of $\beta$ needed to fit the data, the agreement is, we believe, nonetheless satisfactory, and does validate the link proposed here between the two criteria given in ASTM Standard 1304 to test whether the data satisfy the requirement of small scale yielding.

Were it not for the fact that $p$ also detects the presence of residual stresses in the specimens, therefore, one of the two criteria would be redundant. There are, indeed, references where residual stress and not crack tip plasticity causes $p$ to deviate significantly from zero $[23,24]$. Hence, the $p$ criterion has its utility, independently of the relative measure of crack tip plasticity it provides. On the other hand, it is found in Fig. 3 that the experimental curves cross $p=0.1$ near $B=2 B_{\mathrm{c}}$. This shows that, unless $p$ is artificially lowered by the added influence of residual stresses across the test specimen, testing according to ASTM E1304 will actually not provide, on average, a size advantage compared with ASTM E399 if the second requirement, that $p$ fall below 0.1 , must be respected.

This calls into question whether the constant in Eq. (3) specified by the standard should not be 2.5 instead of 1.25 , if only for consistency between the two requirements used to ascertain, for elastoplastic materials, the validity of a testing procedure based on linear elastic fracture mechanics. There are references stating that reliable $K_{\mathrm{I}}$ values have only been measured with Chevron-notched specimens sufficiently large to satisfy $B>2 B_{\mathrm{c}}$; this would imply that specimens as large as ASTM E399 specimens are required with Chevron-notched geometries [6,25]. This, in turn, raises the question of whether the correction procedure suggested by Barker [2] to determine $K_{\text {Ic }}$ on the basis of $K_{\mathrm{Q}}$-values with a finite plasticity parameter $p$ according to 


$$
K_{\mathrm{Ic}} \approx K_{\mathrm{Q}}\left(\frac{1+p}{1-p}\right)^{1 / 2},
$$

should be used to reduce specimen size requirements in Chevron-notched sample tests. Toughness values computed using Eq. (30) did, indeed, yield good agreement with independently measured $K_{\mathrm{Ic}}$ values with $p$ values as high as 0.2 - in another study [21], even 0.25 .

Significantly more data reporting both $p$ and $B / B_{\mathrm{c}}$ are clearly needed, both to test the correlation provided in Fig. 3, and to ascertain by how much $B$ must exceed $B_{\mathrm{c}}$ for valid data to be obtained in the presence of crack tip plasticity. If data show that the Chevron-notched specimen testing procedure does indeed allow for significantly smaller specimen sizes than ASTM E399 in the presence of crack tip plasticity, it is then essential that the upper allowable limit for parameter $p$ be adjusted accordingly. Specifically, if Eq. (3) is to remain a valid lower bound on specimen size, the upper limit for parameter $p$ should, for consistency, be raised to a value near 0.2 (Fig. 3). The transition from $K_{\mathrm{Q}}$ to $K_{\mathrm{Ic}}$ should then probably be made according to Eq. (30) in order to not systematically underestimate the actual fracture toughness.

\section{Conclusion}

An analysis of the influence of crack tip plasticity on the relationship between load and crack mouth displacement for Chevron-notched samples during unload/load cycles, as specified by ASTM Standard E1304 for measurement of plasticity parameter $p$, was conducted according to Irwin's simplified model of the elastic/perfectly plastic crack tip plastic zone. It was found that

1. A correlation exists between $p$, and the ratio of the minimum specimen size required by the standard to the actual specimen size, in the form of a direct proportionality; this is in broad agreement with experimental results found in this study and ones from the literature.

2. The experimental $p$ value interpolated for a specimen size equalling the minimum required by ASTM Standard E1304 is $\approx 0.2$; this is twice the maximum allowed value for $p$.

3. In order to harmonize the validity criteria for the Chevron-notch test in terms of minimum specimen size and upper limit of the plasticity parameter $p$, either the minimum required specimen size or the admissible plasticity parameter $p$ has to be increased. In the former case, one of the major advantages of the Chevron-notch fracture toughness test compared to ASTM Standard E399, namely its smaller specimen geometry, is lost. In the latter case, inclusion in the standard of the conversion from $K_{\mathrm{Q}}$ to $K_{\mathrm{Ic}}$ values based on the plasticity parameter $p$, as proposed by Barker, should be reconsidered.

\section{Acknowledgements}

This work was funded by the Swiss National Science Foundation under contract no. 2100-049119.96. We also wish to thank Dr. M. Diener from the Institut für Metallurgie und Metallforschung of the Swiss Federal Institute of Technology in Zürich for providing the $\mathrm{AlCuMgAg}$ and the $\mathrm{AlZnMg}(\mathrm{Cu})$ material and A. Miserez for providing some additional experimental results.

\section{Appendix A. Onset of large-scale yielding estimated by a limit-load estimation based on a slice model}

The limit load for a short bar specimen of length $W$ and thickness $B$ at critical crack length $a_{\mathrm{c}}=0.55 \mathrm{~W}$ can be estimated through the use of a slice model, as illustrated in Fig. 4. Similar models have been used to 


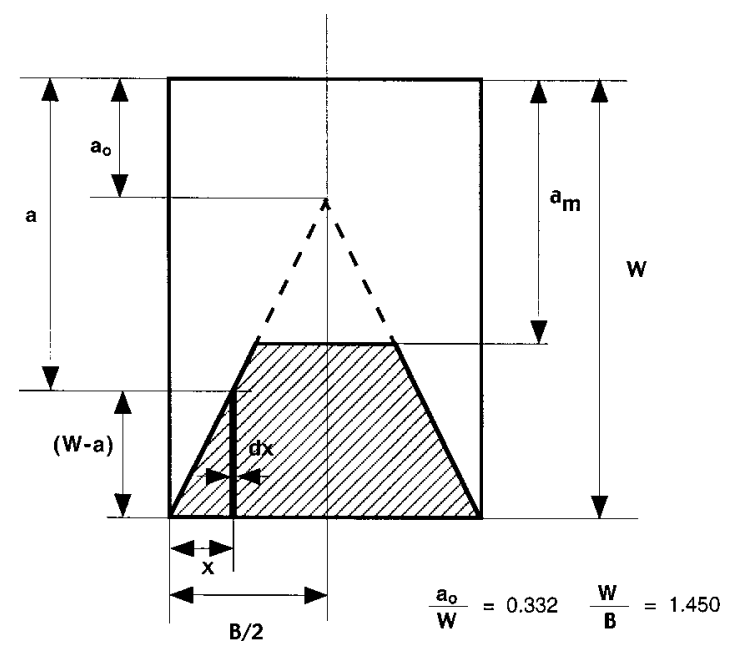

Fig. 4. Schematic of parameters used for the numerical calculation of the limit load at the physical crack length $a_{\mathrm{m}}$ for the critical effective crack length, $a_{\mathrm{c}}$.

estimate the compliance of a Chevron-notched specimen [26], yielding reasonably good agreement with experiments and with more sophisticated 3D finite element modelling.

The limit load for a specimen with a straight-through crack (i.e., a standard double cantilever beam) is given by [11]

$$
P_{\text {limit }}=\gamma(W-a) B \sigma_{\mathrm{y}}
$$

where $(W-a)$ is the uncracked ligament length, $B$, the thickness, $\sigma_{\mathrm{y}}$, the yield strength and $\gamma$ is given by

$$
1.26 \sqrt{\gamma^{2}+\frac{2 W}{(W-a)} \gamma}-\gamma=1 .
$$

By integrating in increments of $\mathrm{d} X$ and appropriately varying the uncracked ligament length $(W-a)$ over the sample width $B$, the limit load for the short-bar specimen in which the crack has advanced to a given crack length can be estimated. Dimensional analysis shows that the limit load is given by

$$
P_{\text {limit }}=\varphi B^{2} \sigma_{\mathrm{y}}
$$

where $\varphi$ is a dimensionless parameter which is a function of the actual physical crack position $a_{\mathrm{m}} / W$, i.e. $\alpha_{\mathrm{m}}$. For $\alpha_{\mathrm{m}}$ close to $\alpha_{\mathrm{c}}$, i.e. the plastic zone is small compared to the specimen size, numerical integration for $\varphi$ yields a value of 0.068 . For the other limiting case where $\alpha_{\mathrm{m}} \approx \alpha_{0}$, which corresponds to complete plastic tearing to advance the equivalent elastic crack to $\alpha_{c}, \varphi$ is 0.097 .

The load $P_{\mathrm{Q}}$ necessary to advance the crack tip is (for the short bar), albeit purely elastic,

$$
P_{\mathrm{Q}}=\frac{1.204}{f(a)} K_{\mathrm{Q}} B^{3 / 2}
$$

with $f(a)=Y_{\mathrm{m}}^{*}=25.11$ at the critical physical crack length $a_{\mathrm{m}}$ for the short bar geometry [13], and using for $\varphi$, the limiting value corresponding to large scale plasticity, i.e. 0.097 , the ratio between $P_{\mathrm{Q}}$ and $P_{\text {limit }}$ can be written as 


$$
\frac{P_{\mathrm{Q}}}{P_{\text {limit }}}=0.442\left(\frac{B_{\mathrm{c}}}{B}\right)^{1 / 2},
$$

which, for $P_{\mathrm{Q}}=P_{\text {limit }}$, determines the position of the vertical line in Fig. 3.

\section{References}

[1] Brown KR. The Chevron-notched fracture toughness test. ASTM Standardization News; 1988. p. 66-9.

[2] Barker LM. Theory for determining $K_{\text {Ic }}$ from small, non-LEFM specimens, supported by experiments on aluminum. Int $\mathbf{J}$ Fract 1979;15(6):515-36.

[3] Munz DG. Determination of fracture toughness of high strength aluminum alloys with Chevron-notched short-rod and short-bar specimen. Engng Fract Mech 1981;15(1-2):231-6.

[4] Eschweiler J, Marci G, Munz DG. Fracture toughness of an aluminum alloy from short-bar and compact specimens. In: Underwood JH, Freiman SW, Baratta FI, editors. Chevron-notched specimens: testing and analysis - ASTM STP 855, ASTM, Philadelphia, 1984. p. 255-69.

[5] Boothby RM, Hippsley CA. Impact and Chevron-notch fracture toughness testing of particulate metal matrix composites. Mat Sci Tech 1994;10(6):565-71.

[6] Brown KR. The use of the Chevron-notched short bar specimen for plane-strain toughness determination in aluminum alloys. In: Underwood JH, Freiman SW, Baratta FI, editors. Chevron-notched specimens: testing and analysis - ASTM STP 855, ASTM, Philadelphia; 1984. p. 237-54.

[7] Purtscher PT, McColskey JD, Drexler ER. Aluminum-lithium alloys: evaluation of fracture toughness by two test standards, ASTM Method E813 and E1304. In: Brown KR, Baratta FI, editors. Chevron-notch fracture test experience: metals and nonmetals - ASTM STP 1172, ASTM, Philadelphia, 1992. p. 110-30.

[8] Bray JW. Use of the Chevron-notched bar test to guarantee fracture toughness for lot release in aluminum alloys. In: Brown KR, Baratta FI, editors. Chevron-notch fracture test experience: metals and non-metals - ASTM STP 1172, ASTM, Philadelphia, 1992. p. 131-43.

[9] Barker LM. Specimen size effects in short-rod fracture toughness measurements. In: Underwood JH, Freiman SW, Baratta FI, editors. Chevron-notched specimens: testing and analysis - ASTM STP 855, ASTM, Philadelphia, 1984. p. 117-33.

[10] Rice JR. Mechanics of crack tip deformation and extension by fatigue. Fatigue crack propagation - ASTM STP 415, ASTM, Philadelphia, 1967. p. 247-309.

[11] Hellan K. Introduction to fracture mechanics. New York: McGraw-Hill, 1984. p. 18 and 45.

[12] Barker LM, Baratta FI. Comparison of fracture toughness measurements by short-rod and ASTM standard method of test for plane-strain fracture toughness of metallic materials. J Test Eval JTEVA 1980;8(3):97-102.

[13] ASTM Standard E1304-89 (reapproved 1997). Standard test method for plane-strain (Chevron-notch) fracture toughness of metallic materials, ASTM, Philadelphia, 1990. p. 863-73.

[14] Barker LM. Compliance calibration of a family of short-rod and short-bar fracture toughness specimens. Engng Fract Mech 1983;17(4):289-312.

[15] Newman Jr JC. A review of Chevron-notched fracture specimens. In: Underwood JH, Freiman SW, Baratta FI, editors. Chevronnotched specimens: testing and analysis - ASTM STP 855, ASTM, Philadelphia, 1984. p. 5-31.

[16] Nicoletto G. Three-dimensional photoelastic calibration of a Chevron-notched short bar fracture specimen geometry. Engng Fract Mech 1986;24(6):879-87.

[17] Orange TW, Bubsey RT, Pierce WS, Shannon Jr JL. Analysis of some compliance calibration data for Chevron-notch bar and rod specimen. In: Brown KR, Baratta FI, editors. Chevron-notch fracture test experience: metals and non-metals - ASTM STP 1172, ASTM, Philadelphia, 1992. p. 54-62.

[18] Eschbach L. Entwicklung von sprühkompaktierten AlCuMgAg-Legierungen mit hoher Warmfestigkeit und Zähigkeit. PhD Thesis no. 12339, ETH Zürich; 1997.

[19] Mächler R. Höchstfeste Sprühkompaktierte Aluminium-Zink-Magnesium-Kupfer-Legierungen. PhD Thesis no. 10332, ETH Zürich, 1993.

[20] Kouzeli M, Weber L, SanMarchi C, Mortensen A. Mechanical behaviour of pressure-infiltrated ceramic particle reinforced aluminum. In: Massard T, Vautrin A, editors. Proc 12th Int Conf on Compos Mater ICCM 12, paper no. 880, Paris, 1999.

[21] Biner SB, Barnby JT, Elwell DWJ. On the use of short-rod/bar test specimens to determine the fracture toughness of metallic materials. Int J Fract 1984;26(3):3-16.

[22] Tschanz TC, Matlock DK, Krauss G. Applicability of the short-rod fracture toughness test to new microalloyed bar steels. In: Brown KR, Baratta FI, editors. Chevron-fracture test experience: metals and non-metals - ASTM STP 1172, ASTM, Philadelphia, 1992. p. 26-42. 
[23] Tingle JR, Shumaker CA, Jones DP, Cutler RA. The effect of binder chemistry on the fracture toughness of cemented tungsten carbides. In: Underwood JH, Freiman SW, Baratta FI, editors. Chevron-notched specimens: testing and analysis - ASTM STP 855, ASTM, Philadelphia, 1984. p. 281-96.

[24] Watson T, Jolles M, Peyser P, Mostovoy S. An evaluation of the short-rod technique to measure fracture toughness of polymers. J Mater Sci 1987;22:1249-58.

[25] Wang C, Yuan M, Chen T. An investigation on the method for determination of fracture toughness $K_{\mathrm{Ic}}$ of metallic materials with Chevron-notched short-rod and short-bar specimens. In: Underwood JH, Freiman SW, Baratta FI, editors. Chevron-notched specimens: testing and analysis - ASTM STP 855, ASTM, Philadelphia, 1984. p. 193-204.

[26] Munz D, Bubsey RT, Srawley JE. Compliance and stress intensity coefficients for short-bar specimen with Chevron-notches. Int J Fract 1980;16:359-74. 